\title{
Knowledge Management Methodology: Developing a Phenomenalogical Middle-range Thinking Approach for Knowledge Management Research
}

\author{
Fahmi Ibrahim \\ School Of Business \\ Universiti Teknologi Brunei
}

Received: Feb. 26, 2017

Accepted: Oct. 3, 2017

Published: October 5, 2017

doi:10.5296/jmr.v9i4.10790

URL: https://doi.org/10.5296/jmr.v9i4.10790

\begin{abstract}
In light of the fact that KM research and practice embraces a wide range of activities and interest, complexity emerges when consideration is given to the actual conduct of research to be undertaken. Drawing from numerous literature, KM covers, on the one hand, technological interventions (objectivist perspective) that aim to support knowledge sharing, while on the other hand, it also covers the appreciation of social approaches (practice-based perspective) that emphasise the importance of people in sharing knowledge. Due to the fact that KM covers such a broad spectrum of area, it calls for greater scrutiny into the way that research is undertaken. The aim of this paper is to discuss the methodological issues within which the KM study should be undertaken. The paper considers the appropriateness of a particular methodology stance for the KM research while focusing on research processes. In particular, a phenomenological approach to middle-range theory is used to develop a comprehensive framework of KM as context of the study. The rationale for using a phenomenological to middle-range theory is provided from the viewpoint that it requires researchers to focus on developing theory which produces explanations that are arguably a more realistic depiction of the hard/technical and soft/social nature of KM practices.
\end{abstract}

Keywords: Knowledge Management methodology, Knowledge Management research, phenomenology, middle-range theory. 


\section{Introduction}

Over the past decade, KM has come into the limelight and received considerable attention from academics and practitioners. In relation to this phenomenon, Grant (2001:p.27) suggests that 'among the innovations that have swept through the world of management during the past two decades......KM has probably aroused the greatest interest and made the biggest impact'. The most significant factor of this phenomenon is the recognition of the importance of knowledge as a critical resource for organisations (Drucker, 1998; Nonaka, 1991; Davenport and Prusak, 1998; Prusak, 1997; Leornard-Barton, 1995). Thus, knowledge is claimed as the main distinguishing factor of business success and competitive advantage (Carlucci and Schiuma, 2006; Pan and Scarborough, 1999). Moreover, the environmental change has led to a new perspective in management thinking to recognise knowledge as a strategic asset and a source of competitive advantage (Leonard Barton, 1995; Nonaka, 1991; Grant, 1996) which appears to follow a significant shift in the business environment from an industrial economy to the new economy. The fundamental principles underlying this new economy are dramatically different to the traditional concepts of how value is created to make organisations successful. The fundamental principle has shifted from relying on classical factors of production, such as land, labour and capital to 'knowledge' as a primary resource for the new economy (Drucker, 1994). It is argued that in the new economy knowledge can replicate and multiply endlessly, while material resources cannot; natural resources deplete with use, but knowledge expands with use (Allee, 1999).

Nevertheless, there is considerable ambiguity in the KM terminology, which has led to fragmented debate on the topic (Bollinger and Smith, 2001). Hence, it is argued that KM is a complex area that brings together hard, soft and abstract aspects; IT issues related to KM tools, organisational issues related to culture, as well as fundamental philosophical issues with regard to different epistemological views of knowledge. Recent findings shown lacked of cumulativeness and consistency in the current KM debate (Mariano and Awazu, 2016). This often results in the implementation of KM initiatives with either an overemphasis on technology (hard aspects) to the exclusion of adequate people management (soft aspects) or strong people management programmes hindered by inadequate enabling technologies (Moffett et al., 2003:p. 6). ). In fact the theory of KM amalgamates a cluster of theories from existing research fields with unique directions and innovative concepts on its own (Baskerville and Dulipovici , 2006). However, there are challenges to establishing KM as separate discipline due to its conceptual plurality (Nonaka and Peltokorpi, 2006) as KM itself evolved from a spectrum of theoretical traditions ranging from philosophy to computer science considered to be a mixed bag of idealistic theories without a coherent theoretical base (Alvesson and Karreman, 2001). In addition study recent study tracing the historical origins of KM issues through Referenced Publication Years Spectroscopy has shown that KM issues are rooted in the areas of economics, marketing, social networks analysis, organisational learning and economic sociology (Khasseh and Mokhtapour, 2016). Findings from Wallace et. al (2011) study also demonstrates 60 percent employed mainstream social sciences research methodologies and the remaining using an identifiable methodology were characterized by the use of "provisional methods" that appeared to substitute for more 
formally defined or scientifically based research methodologies. Whereas meta-data analysis findings by Dwivedi et. al (2011) suggest that a combination of positivist, empirical, conceptual/descriptive, and multi-method approaches have been predominantly used in the area. Likewise longitudinal analysis of KM development and related studies by Lee et. al (2012) reflect that the coverage of key KM papers has expanded into a broad spectrum of disciplines.

The main issue which emerge from research in $\mathrm{KM}$ is the degree to which research still focuses on the domain of managing explicit knowledge despite avowed recognition of the importance tacit knowledge (Kane et. al, 2006). This suggests to explain that many contemporary KM studies adopt quantitative methods in comparison to qualitative research. Other issue is the methodological stance not always evident, which result in criticism that the research position is ambiguous and therefore problematic for other researcher to construct a possible stance by piecing together aspects of the data collection and analysis to design a possible methodology (Kane et. al, 2006).

Against this backdrop, relatively little attempt has been made the appropriateness of a particular methodology stance for undertaking KM research. In essence, how should research into KM can be done? Therefore, the aim of this paper is to discuss the methodological issues within which the KM study should be undertaken. The following section provides an overview of the two main perspectives of KM. The second section discusses what research methodology is, how and why research methodology is related to ontology, epistemology and methodology stances, and to what extent deduction and induction approaches are important in carrying out the qualitative research. The objective is to provide a methodological stance of conducting the research. The third section describes the research design discusses how and why the in-depth qualitative interviews approach is appropriate for KM research. The penultimate section focuses on the defence of the methodological stance taken, to demonstrate the quality and strength of methodology adopted upon which the validity of KM research.

\section{Knowledge Management Perspectives}

In this section, a brief summary of selected KM literature related to main issues of KM practices in two different perspectives is discussed. This is central in order to provide a theoretical background of KM. For the purpose of this study, knowledge is defined based on two broad epistemological camps in the contemporary debate on the nature of knowledge, identified by Hislop (2005:p.14): objectivist perspective (explicit knowledge) and practice-based perspective (tacit knowledge). For example, authors such Cook and Brown (1999) and Asudani (2005), refer to the objectivist perspective as epistemology of possession, where knowledge is regarded as an asset (Empson, 2001), 'stock' (Fahey and Prusak, 1998) and static (Newell et al., 2002). Such knowledge can exist in the form of documents, operating procedures, computer systems or databases. On the other hand, the practice-based perspective conceptualises knowledge as socially constructed and inherently tacit. This perspective is labelled as 'epistemology of practice' (Cook and Brown ,1999) where knowledge is regarded as 'flow' (Fahey and Prusak, 1998) and process (Empson, 2001). The 
central issue of this perspective is that knowledge resides in the human mind and is dependent on the knower (Venzin et al., 1998). These perspectives, in turn, not only provide an insight into how the nature of knowledge has been conceptualised, but also provides the roots of KM practices, based on the different assumptions of knowledge.

For instance, for KM practice - objectivist perspective, there is an acknowledgement that much of organisational knowledge may be tacit and it is possible to convert this knowledge into explicit form. For example, all the instructions for operating machines may not be totally explicit but, with the expertise and experience of workers operating them, it is possible to make all the knowledge explicit and codify it into a complete set of standard operating procedures. The primary role of this kind of KM perspective is to allow knowledge to be shared widely and effectively within or across organisations, so that best practices, problem solutions and procedures can be shared. Technology, includes hardware, software or other means of processing, storing, capturing and organising data or information plays a major role in this $\mathrm{KM}$ process. The characteristics of this $\mathrm{KM}$ perspective can be defined as the first generation KM (McElroy, 2003:p.xxiv) as there was strong emphasis on IT in many of the earliest KM initiatives. This has become known as the 'supply side of KM' which consists of capturing, codifying, and sharing valuable knowledge, and also involves getting the right information to the right people at the right time.

In contrast to objectivist perspective, the practice-based perspective conceptualises knowledge not as a codifiable entity, but instead emphasises that knowledge is socially constructed and is inherently tacit. This perspective defines knowledge in dynamic terms, regarding it as a practice of doing or knowing rather than static or objective- knowledge which people possess (Newell et al., 2002:p.7). Cook and Brown (1999) labelled this perspective as an 'epistemology of practice' due to the centrality of human activity to its conception of knowledge. In other words, knowledge resides in mind, body and social systems, which are dependent on the context and the knower (Venzin et al., 1998:p.43). Therefore, the nature of knowledge which is rooted and manifested in the human mind and activity represents the characteristics of knowledge from a practice-based perspective. As noted by Hislop (2005:p.29-34) that tacit and explicit knowledge are inseparable. They are not two ends of a continuum, but two sides of the same coin (Tsoukas, 2005: p.158). The consequence is that there is no such thing as completely explicit knowledge, as all knowledge will have a tacit dimension or will remain tacit, and therefore resistant to articulation or codification (Newell et al., 2002:p.7). Thus, the view of explicit knowledge which stands on its own, would reduce the ineffability of tacit knowledge and narrow all knowledge to only what can be articulated (Tsoukas, 2005:p.158). In view of that, from this perspective, it is impossible to totally codify knowledge into fully explicit form. There will be an element of tacit knowledge which is still embodied in people. The practice-based perspective argues that all knowledge is socially constructed which is purely subjective to interpretations from people. A general model of KM practice-based perspective is focused on knowledge sharing through rich interactions, knowledge sharing culture that motivating people to share knowledge instead of hoarding their knowledge by establishing networked relationship and trust (Davenport and Prusak, 1998). 
By the same token, drawing from the work of Andriessen (2008) addresses the way knowledge is conceptualised in KM literature and practice. Using the work of Lakoff and Johnson (1999) on metaphors it will show how people use metaphors to think and talk about knowledge. It is widely used 'Knowledge as Stuff' (objectivist) metaphor that Gustavsson (2001) called 'thingification'. So the metaphors assumes that knowledge is objective, that is can be stored and retrieved without any distortion can be transferred from one human being to another without interpretation. In contrast, 'Knowledge as Love' (subjectivist) related to the accessibility of knowledge, pre conditions of knowledge work and well- being of knowledge workers in the organisation.

Having established both the fundamental of KM perspectives, it provides the philosophical background and mainly ontological stance of KM related to research methodology that is discussed in the following section.

\section{What is research methodology?}

Research methodology is important to understand because it can characterise a systematic investigation of a research problem. It refers to the procedural framework within which research is conducted, and thus provides guidelines on how research should be conducted (Remenyi and Williams, 1995). Further, Kaplan (1964:p.23) emphasises that the aim of research methodology is 'to help us to understand, in the broadest possible terms not the products of scientific inquiry but the process itself'. In other words, the process of research inquiry has to be carried out diligently, critically, objectively and logically with the desired end to 'discover new facts that will help us to deal with the problem situation' (Sekaran, 1992:p.4). This can be illustrated through a broader definition the concept of research offered by Preece (1994):

"Research is conducted within a system of knowledge and that research should be probing or testing that system with the aim of increasing knowledge. The increase in knowledge may be something entirely new and original or, more commonly, it may consist of checking, testing, expanding and refining ideas, which are still provisional. In particular, research should continually question the nature of knowledge itself, what it is and how it is known" (Preece, 1994:p.18).

However, the researcher must be 'objective' in the research process that has become a controversial issue in philosophical debates and the methodological stances in social research. This is related to the question of what the nature of knowledge is and how it is known is commonly underpinned by a basic set of beliefs that define the researcher's world view. This basic set of beliefs is known as a paradigm (Guba, 1990:p.17) and provides guideline on how this research is conducted which consist of three main elements to an inquiry paradigm: ontology, epistemology and methodology are summarised in Table 1 below: 


\section{$\triangle$ Macrothink}

Table 1. Implications of Ontological Stance on Epistemology and Methodology

\begin{tabular}{|c|c|c|c|c|}
\hline Ontology & $\begin{array}{l}\text { Realism } \\
\text { an external reality } \\
\text { exists independent of } \\
\text { our beliefs or } \\
\text { understanding }\end{array}$ & \multicolumn{2}{|c|}{$\begin{array}{l}\text { Materialism } \\
\text { an external reality } \\
\text { exists independent of } \\
\text { our beliefs or } \\
\text { understanding, but, } \\
\text { only the material and } \\
\text { physical world is } \\
\text { considered reality }\end{array}$} & $\begin{array}{l}\text { Idealism } \\
\text { reality is only } \\
\text { knowable through } \\
\text { human mind and } \\
\text { socially constructed } \\
\text { meanings }\end{array}$ \\
\hline Epistemology & \multicolumn{2}{|c|}{$\begin{array}{l}\text { Positivism } \\
\text {-the reality is independent and } \\
\text { unaffected by the researcher } \\
\text {-facts are concrete and possible } \\
\text { to conduct value-free inquiry }\end{array}$} & \multicolumn{2}{|c|}{$\begin{array}{l}\text { Interpretivism } \\
\text {-the researcher and reality } \\
\text { dependent on each other } \\
\text {-the facts are all human creations } \\
\text { and not possible to conduct } \\
\text { value- free research }\end{array}$} \\
\hline Methodology & \multicolumn{2}{|c|}{$\begin{array}{l}\text { Deductive } \\
\text { the research process begins with } \\
\text { theory and hyphothesis } \\
\text { verification/falsification }\end{array}$} & \multicolumn{2}{|c|}{$\begin{array}{l}\text { Inductive } \\
\text { the exploration and analysis that } \\
\text { leads to theory development } \\
\text { sense-making/understanding }\end{array}$} \\
\hline
\end{tabular}

Source: Adapted from Snape and Spencer (2003:p.16) and Punch (2005:p.12)

Table 1 illustrates the ontological stance and indicates the link to epistemological and methodological positions that usually leads the researcher to adopt methods that are characteristic of that position. However, for the purpose of this paper, only two ontological perspectives are discussed briefly. For 'realist' (realism) start with the position that reality is concrete and external (i.e. explicit knowledge), therefore, the methodology in this paradigm should be objective and impartial as well as immune from the influence of researchers' values and beliefs (value-free). The quantitative method with deductive approach (hypotheses testing) is commonly deployed by researchers in this paradigm (Hussey and Hussey, 1997). However, for 'idealist' (idealism) asserts that reality is socially constructed meanings and only knowable through the human mind (i.e. tacit knowledge). Therefore, a social researcher has to explore and understand the social world through the participants' and their own perspectives; explanations can only be offered at the level of meaning rather than cause. Qualitative method, largely with the inductive approach (theory development) is associated with idealism perspective. In brief, research methodology concentrates on the issue of how the researcher collects knowledge about the world or reality and indicates a combined set of techniques to guide research, whose claims can be evaluated (Easterby-Smith, 2002). These combinations of techniques are derived from the logical or philosophical assumptions 
(ontology and epistemology) concerning the phenomenon that is being investigated (Morgan and Smircich, 1980).

The most substantial issue of the brief discussion above is to guide the process of KM research that adopts an idealism perspective with interpretivism stance that will be discussed in following section. However, the element of induction-deduction or deduction-induction approach was adopted in flexible ways during the research process as an open mind is impossible because preconceptions exist and affect what is seen and interpreted (Shipman, 1997:p.42). This is related to the role of theory in research that is discussed extensively in section 5. The following section will illustrate how the stances on the ontology, epistemology and methodology of KM research have been made, and why.

\section{Methodological Considerations}

The quality, strength and validity of KM research would be measured largely by the appropriateness of the methodology. The KM study must be designed in such a way as to reject 'methodological orthodoxy in favour of methodological appropriateness as the primary criterion for judging methodological quality by recognising that different methods are appropriate for different situations' (Patton, 2002:p.72). Hence, methodological quality should be judged on whether one has made sensible methods decisions given the purpose of the inquiry, the questions being investigated, and the resources available (Patton, 2002).

In view of the KM research, it was clear at the outset that the field should be exploratory in nature. Majority qualitative methodological approaches were adopted in KM research indicated by recent study by Mariano and Awazu (2016). In adopting this stance, emphasis should be placed on the aim and objectives of the research, not on formulating hypotheses. Exploratory studies are a valuable means of discovery because the purpose is to find out 'what is happening, to seek new insights, to ask questions and to assess phenomena in new light' (Robson, 1993:p.59). Therefore, the exploratory, unfolding nature of the KM study, which is guided by the literature, formed a conscious part of the methodology. The purpose is to retain an open mind in understanding the KM theories and concepts without being enslaved by existing literature. It is important to pay attention to the existing theories and research that are relevant to the study, because these are often key sources for understanding what is going on within the KM phenomena. However, the literature 'is treated not as authority to be deferred to, but as a useful yet fallible source of ideas what is going on' (Maxwell, 1996:p.27). Further, the literature is used as a 'jumping-off point' to extend the ideas and build the theory (Rubin and Rubin, 2005:p.236). Conversely, such an argument turns toward examining the role of theory used in this study. Although, generally, the role of theory in phenomenology research is controversial (Ray, 1994:p.123), the theory was used to provide a focus for the study, to assist in formulating and reformulating the problem posed in the research, to discover new dimensions of the research problem (Bensman and Vidich, 1960:p.582) and further guide the research process (Ray, 1994). The theory in this study was used more as a sensitising device to view the world in a certain way (Klein and Myers, 1999:p.75). It is important to note that KM study maintains that theory generation takes place when all the data can be generated through in-depth interviews. The data is conceptualised 
and theorised into categories and themes, and integrated into concepts and theories that emerge during the research process and are also suggested in the literature. Such an approach emphasises theory generation rather than theory testing, with theory being developed inductively from the data. However, it is cautioned that theory generation in such qualitative research is inclined with scepticism and suspicion due to the lack of clarity and standardisation of methods, as opposed to theory testing (Easterby-Smith et al., 1991:p.37).

In light of the defence discussed above, KM research should adopt Laughlin's (1995) 'middle-range thinking' approach in terms of theoretical perspectives. From a theoretical perspective the 'medium' position is arguably a more realistic depiction of the hard/technical and soft/social nature of KM. This argument is consistent as it was reported that the trend for KM practices over the years 1998-2004 was to use a mixed strategy based on the combination of technology and personalisation (Perrin et al., 2007:p. 160). As is recognised, in the practice-based (human/people based) and objectivist-based (IT based) spectrum of KM research, KM practices are not purely some technical and context-free phenomenon, as was suggested in first generation KM. It would be argued against the importance of depicting this context as part of any theory of KM. This is because to adopt a 'high' level theory of KM can be likened to any other scientific theory. For example, theory of gravity, where it does not matter whether it is an apple or a bicycle or any other objects that is falling to the ground since all differences can be expressed through the theory of weight and volume. But a 'high' level theory in KM becomes equally uninterested because KM practices are also social practice that cannot be explained through scientific lens. On the other hand, a 'low' emphasis to prior theory, suggests all contextual variables are unique and only applicable to the KM practices being explored. It becomes invariably impossible to detach all contextual diversity into theoretical categories (context-free) leaving the richness of the picture to be portrayed largely 'as it is' without theoretical refinement. In this situation, no learning or theory from other situations is possible and appropriate. Nevertheless, the 'middle-range thinking' approach recognises a material reality distinct from our interpretations while at the same time does not dismiss the inevitable perceptive bias of understanding. This argument is in line with the concept of 'objectivity' from the phenomenological perspective. Objectivity is 'fidelity to phenomena which is defined as a refusal to tell the phenomena what it is, but a respectful listening to what the phenomena speaks of itself' (Colaizzi, 1978:p.52). According to Colaizzi (1978) objectivity, then, is required to recognise and affirm both our own perceptions or presuppositions (he uses the term 'experience') and the perceptions of others. It is simply stated that the assumptions are there and it cannot be objectively eliminated and avoidable completely (Colaizzi, 1978). Thus, it is clearly impossible to eliminate researcher's theories or preconceptions of what has been called inherent reflexivity (Hammersley and Atkinson, 1995:p.16-17).

Therefore, theory being generated will be always be 'skeletal' requiring empirical detail to make them meaningful. The empirical data is of vital importance because it complements and completes the 'skeletal' theory derived from the literature. Laughlin (1995:p.82) expresses this as a 'skeletal' theory always requires diverse empirical 'flesh' to arrive at meaningful 'whole beings'. Others have conceptualised this in terms of 'abductive reasoning' as it allows 
dynamic interaction between data and theory (Coffey and Atkinson, 1996:p.156). Moreover, 'theory without data is empty; data without theory is nothing' (Silverman, 2000:p.253). Thus, empirical work in research will contribute significantly in terms of theory building guided by the literature.

\section{Conclusions}

This paper begins with a review of two main KM perspectives; objectivist and practice-based perspective that are related to the philosophical understanding of conducting KM research. Given that KM amalgamates a cluster of theories from existing research fields and further due to its conceptual plurality as KM itself evolved from a spectrum of theoretical traditions ranging from philosophy to computer science/IT, there are challenges to adopt appropriate methodology stance in undertaking KM research. Also, in view of the trend of KM practices to use mixed strategy based on the combination of technology and personalisation, it will be crucial for designing research methodology. This paper posits rest on the belief that as a research methodology, it is unproblematic if it is accepted to develop phenomenology approach with middle-range thinking based upon ontology and epistemology considerations of particular KM research that will be undertaken. In other words, the use of qualitative research methodology is recommended as opposed to a quantitative one. It is suggested that one of the major underlying weaknesses of developing a research methodology, particularly in $\mathrm{KM}$ centres on this tension; social research is sacrificed at the expense of a desire to be seen to be scientific.

The discontinuity in $\mathrm{KM}$ research, largely, is due to the fact that $\mathrm{KM}$ literature provides testimony to the infancy of its research methodology given that the study of KM is a complex subject which involves interdisciplinary analysis and debate about culture and IT/IS dimensions. This contributes to the non-standardised approaches which were adopted in previous research. Thus, this paper provides an alternative view on methodology stance and future direction for academics in undertaking KM research.

\section{References}

Allee, V. (1999). The art and practice of being revolutionary. Journal of Knowledge Management, 3(2), 121-131. https://doi.org/10.1108/13673279910275576

Alvesson, M., \& Karreman, D. (2001). Odd Couple: Making Sense of the Curious Concept of Knowledge Management. Journal of Management Studies, 38(7), 995-1018. https://doi.org/10.1111/1467-6486.00269

Andriessen, D. G. (2008). Stuff or Love? "How metaphors direct our efforts to manage knowledge in organisations. Knowledge Management Research \& Practice, 6, 5-12. https://doi.org/10.1057/palgrave.kmrp.8500169

Assudani, R. H. (2005). Catching the chameleon: Understanding the elusive term knowledge. Journal of Knowledge Management, $\quad 9(2), \quad 31-44$. https://doi.org/10.1108/13673270510590209 
Baskerville, R., \& Dulipovici, A. (2006). The theoretical foundations of knowledge management. Knowledge Management Research \& Practice, 4, 83-105 https://doi.org/10.1057/palgrave.kmrp.8500090

Bensman, J., \& Vidich A. (1960). Social Theory in Field Research. American Journal Sociology, 65(6), 577-584. https://doi.org/10.1086/222788

Bollinger, A. S., \& Smith, R. D. (2001). Managing organizational knowledge as strategic asset. Journal of Knowledge Management, $\quad$ 5(1), 8-18. https://doi.org/10.1108/13673270110384365

Carlucci, D., \& Schiuma, G. (2006). Knowledge Value Spiral: Linking Knowledge Assets to Company Performance. Knowledge and Process Management, 13(1), 35-46. https://doi.org/10.1002/kpm.243

Coffey, A., \& Atkinson, P. (1996). Making Sense of Qualitative Data, Sage, London.

Colaizzi, P. F. (1978). Psychological Research as the Phenomenologist Views It, In Valle R S and King M (Eds), Existential-Phenomenological Alternatives for Psychology, Oxford University Press, New York.

Cook, S.D.N, \& Brown, J. S. (1999). Bridging Epistemologies: the Generative Dance between Organizational Knowledge and Organizational Knowing. Organization Science, 10(4), 381-400. https://doi.org/10.1287/orsc.10.4.381

Creswell, J. W. (1998). Qualitative Inquiry and Research Design: Choosing Among Five Traditions, Sage, London.

Davenport, T. H., \& Prusak, L. (1998). Working Knowledge: Managing What Organization Knows, Harvard Business School Press, Boston, MA.

Drucker, P.F. (1994). Post-Capitalist Society. Harper Business, New York.

Drucker, P. F. (1998). The Coming of the New Organization, In Harvard Business Review on Knowledge Management, Harvard Business School Press, MA.

Dwivedi, Y K, Venkitachalam, K, Sharif, A M, Al-Karaghouli, W., \& Weerakkody, V. (2011). Research Trends in Knowledge Management: Analysing the past and predicting the future. Information Systems Management, 28(1), 45-36. https://doi.org/10.1080/10580530.2011.536112

Easterby-Smith M., Thorpe R., \& Lowe, A. (1991). Management Research: An Introduction, Sage, London.

Easterby-Smith M, Thorpe R, \& Lowe A. (2002). Management Research: An Introduction, 2nd Edition, Sage, London.

Empson, L. (2001). Fear of Exploitation and Fear of Contamination: Impediments to Knowledge Transfer in Mergers between Professional Service Firms. Human Relations, 54(7), 839-862. https://doi.org/10.1177/0018726701547003 
Fahey, L. and Prusak. L. (1998). The Eleven Deadliest Sins of Knowledge Management. California Management Review, 41(3), 265-276. https://doi.org/10.2307/41165954

Grant, R. M. (1996). Toward a Knowledge-Based Theory of the Firm. Strategic Management Journal, 17, Special Issue, pp 109-122. https://doi.org/10.1002/smj.4250171110

Grant, R. M. (2001). Knowledge and Organization, In Nonaka I and Teece D (Eds), Managing Industrial Knowledge: Creation, Transfer and Utilization, Sage, London. https://doi.org/10.4135/9781446217573.n8

Guba, E. G. (1990). The alternative paradigm dialog, In Guba E G (Ed), The Paradigm Dialog, Newbury Park, CA, Sage.

Gustavsson, B. (2001). Power over meaning; unlearning and human values, In Chakraborty, S. K. (Ed), Management of Power-Ethicaland Values Aspects, pp 339-358, Oxford University Press, Delhi.

Hammersley, M., \& Atkinson, P. (1995). Ethnography: Principles In Practice, 2nd Edition, Routhledge, New York.

Hirschheim, R. A. (1992). Information System Epistemology: An Historical Perspective, In Galliers, R. (Ed), Information Systems Research: Issues, Methods and Practical Guidelines, Blackwell Scientific Publications, Oxford.

Hislop, D. (2005). Knowledge Management in Organisations. Oxford University Press, New York.

Hussey, J., \& Hussey, R. (1997). Business Research: A practical guide for undergraduate and postgraduate students, Macmillan Press Ltd., London. https://doi.org/10.1007/978-1-349-25262-6

Kane, H, Ragsdell, G., \& Oppenheim, C (2006). Knowledge Management Methodologies. The Electronic Journal of Knowledge Management, 4(2), 141-152.

Kaplan, A. (1964). Methodology For Behavioural Science: The Conduct of Inquiry, Chandler Publishing Company, USA.

Khasseh, A. A. (2016). Tracing the historical origins of knowledge management issues through referenced publication years spectroscopy (RPYS), Journal of Knolwedge Management, 20(6), 1393-1404. https://doi.org/10.1108/JKM-01-2016-0019

Klein, H. K., \& Myers, M. D. (1999). A Set of Principles for Conducting and Evaluating Interpretive Field Studies in Information Systems. MIS Quarterly, 23(1), 67-94. https://doi.org/10.2307/249410

Lakoff, G., \& Johnson, M. (1999). Philosophy in the Flesh, Basic Books, New York.

Laughlin, R. (1995). Methodological Themes: Empirical research in accounting: alternative approaches and a case for "middle-range" thinking. Accounting, Auditing \& Accountability Journal, 8(1), 63-67. https://doi.org/10.1108/09513579510146707 
Lee, M R., \& Chen T T (2012), Revealing research themes and trends in knowledge management. From 1995 to 2010, Knowledge Based Systems, 8, 45-36. https://doi.org/10.1016/j.knosys.2011.11.016

Leornard-Barton, D. L. (1995). Wellsprings of knowledge: building and sustaining the sources of innovation. Harvard Business School Press, Boston, MA.

Mariano, S., \& Awazu, Y. (2016). Artifacts in knowledge management research: a systematic literature review and future research directions, Journal of Knowledge Management, 20(6), 1333-1352. https://doi.org/10.1108/JKM-05-2016-0199

Mason, J. (1996). Qualitative Researching, Sage, London.

Maxwell, J. A. (1996). Qualitative Research Design: An Interactive Approach, Sage, USA.

McElroy, M. (2003). The New Knowledge Management: Complexity, Learning, and Sustainable Innovation, Butterworth-Heinemann, MA.

Moffett, S., McAdam, R., \& Parkinson, S. (2003). An empirical analysis of knowledge management applications. Journal of Knowledge Management, 7(3), 6-26. https://doi.org/10.1108/13673270310485596

Morgan, G., \& Smircich, L. (1980). The Case for Qualitative Research. Academy of Management Review, 5(4), 491-500.

Newell, S., Robertson, M., Scarbrough, H., \& Swan, J. (2002). Managing Knowledge Work. Palgrave Macmillan, New York.

Nonaka, I. (1991). The Knowledge Creating Company. Harvard Business Review, November-December, pp 96-104.

Nonaka, I., \& Peltokorpi, V. (2006). Objectivity and Subjectivity in Knowledge Management: A Review of 20 Top Articles. Knowledge and Process Management, 13(2), 73-82. https://doi.org/10.1002/kpm.251

Pan, S. L., \& Scarborough, H. (1999). Knowledge Management in Practice: An Explanatory Case Study. Technology Analysis \& Strategic Management, 11(3), 359-374. https://doi.org/10.1080/095373299107401

Patton, M. Q. (2002). Qualitative Evaluation and Research Methods, 3rd Edition, Sage, USA. Perrin, A., Rolland, N., \& Stanley, T. (2007). Achieving best practices transfer across countries. Journal of Knowledge Management, 11(3), 156-166. https://doi.org/10.1108/13673270710752171

Preece, R. A. (1994). Starting research: an introduction to academic research and dissertation writing, Cassels, London.

Prusak, L. (1997). Introduction to Knowledge in Organizations, In Prusak L, (Ed), Knowledge in Organizations, Butterworth-Heinemann, MA. https://doi.org/10.1016/B978-0-7506-9718-7.50003-2 


\section{Macrothink}

Journal of Management Research

ISSN 1941-899X

2017, Vol. 9, No. 4

Ray, M. A. (1994). The Richness of Phenomenology: Philosophic, Theoretic, and Methodologic Concerns, In Morse, J. M. (Ed), Critical Issues in Qualitative Research Methods, Sage, USA.

Remenyi, D., \& Williams, B. (1995). Some aspects of methodology for research in information systems. Journal of Information Technology, 10, 191-201. https://doi.org/10.1057/jit.1995.23

Ritchie, J. (2003). The Application of Qualitative Methods to Social Research, In Ritchie, J. and Lewis, J. (Eds), Qualitative Research Practice: A Guide for Social and Researchers, Sage, London.

Ritchie, J. and Spencer, L. (2002). Qualitative Data Analysis for Applied Policy Research. In Huberman, A., M. and Miles, M. B. (Eds), The Qualitative Researcher's Companion, pp 305-329, Sage, Thousands Oaks.

Robson, C. (2002). Real World Research, 2nd Edition, Blackwell, MA.

Sekaran, U. (1992). Research Methods for Business. A Skill Building Approach, 2nd Edition, New York, John Wiley and Sons.

Shipman, M. (1997). The Limitations of Social Research, 4th Edition, Longman, New York.

Silverman, D. (2005). Doing Qualitative Research: A Practical Handbook, 2nd Edition, Sage, London.

Snape, D., \& Spencer, L. (2003). The Foundations of Qualitative Research, In Ricthie, J. and Lewis, J. (Eds), Qualitative Research Practice: A Guide for Social Science Students and Researchers, London, Sage Publications.

Tsoukas, H. (2005). Complex Knowledge: Studies in Organizational Epistemology. Oxford Press, New York.

Wallace, D. P., Van Fleet, C., \& Downs L.J. (2011). The research core of knowledge management literature. International Journal of Information Management, 31(1), 114-20. https://doi.org/10.1016/j.ijinfomgt.2010.10.002

Venzin, M., von Krogh, G., \& Roos, J. (1998) Future research into Knowledge Management, In von Krogh, G., Roos, J. and Kleine, D., (Eds), Knowing in Firms: Understanding, Managing and Measuring Knowledge, pp 26-66, Sage Publications, London. 